\title{
Fabrication and Characterization of Bioglass
}

\author{
Dalveer Singh, Sandeep Singh and Gurpreet Singh \\ Department of Mechanical Engineering, Punjabi University Patiala, Punjab, India \\ E-Mail: dalvirhans@gmail.com
}

\begin{abstract}
Glasses are common in use now days. These are used in different applications like domestic, automobile, telecommunication etc. The glasses are very useful materials because of their impressive properties. Few years back a new generation of glasses were developed i.e. bioactive glasses and bioactive glass ceramics. The glasses are used for bone grafting now-a-days because of their impressive bioactive properties. These glasses have tendency to form bonds with the living tissue organs. The future of these glasses will be bright in dental, orthopedics and prosthetic applications. In the present work borosilicate glasses of different compositions have been studied. The different elements were added with appropriate mol\% to compose a new bioglass composition. The samples were prepared by melt quench route. The samples were immersed for 21 days in SBF. The samples were characterized before and after immersion in SBF by different techniques. The XRD technique was done to confirm the amorphous nature of glass before immersion and after immersion. The SEM and EDX were done to check the changes on the surface after immersion. The sample $\mathrm{S} 1$ has better biocompatibility results than $\mathrm{S} 2$ andS3. The formation of apatite on the glass samples were confirmed by all techniques mentioned above.

Keywords: Bioactive glass, Characterization, Orthopaedic applications.
\end{abstract}

\section{INTRODUCTION}

The bioglasses are highly promising materials which are used now days because of these have tendency to bonds with living tissue organs [1].These materials have tendency to generate apatite on their surface after exposed to the SBF or human body plasma. The bioglass of composition elements silica $\left(\mathrm{SiO}_{2}\right)$, sodium $(\mathrm{Na})$, calcium $(\mathrm{Ca})$ and phosphorous (P) oxides was prepared by Hench for the first time and named as $45 \mathrm{~S} 5$ bioglass. The $45 \mathrm{~S} 5$ bioglass was prepared with $45 \%$ of silica(Si ), $24.5 \%$ of sodium oxide $\left(\mathrm{Na}_{2} \mathrm{O}\right), \quad 24.5 \%$ of calcium oxide $(\mathrm{CaO})$ and $6 \%$ phosphorous pent-oxide $(P \quad$ ) (in weight\%) composition elements [2]. In later the additions were done to the compositions to enhance the various properties of the bioglass. The bioactivity of bioglasses is concerned with the apatite generation on their surfaces when exposed to the biological fluids[3]. The generation of apatite may be of form HA (hydroxyapatite) or HCA (hydroxyl carbonate apatite). The apatite generation on their surface after exposure to the biological fluids make them useful in dental and orthopedic (such as bone replacements and bone regenerations) applications [5]. The apatite layer is generated due to several reactions taken between the biological fluids and the bioactive glass [6].The apatite generation on the surface of bioglass depends upon various factors like composition of glass, structure of glass, temperature at which it is prepared and solution used for immersion etc. $[6,7,8]$. The changes in compositional elements can affect the properties of bioglass and its melting conditions $[9,10]$. The melting temperature for bioglasses is taken as higher i.e. above $1400^{\circ} \mathrm{C}$ but the $45 \mathrm{~S} 5$ is fabricated at lower temperature $\left(1300^{\circ} \mathrm{C}\right)$ and longer time period [11].Thus, the work is done to develop a new compositions based upon silica, borate, sodium, calcium and phosphorous oxide system. The melting temperature is taken as lower. The apatite generation was tested after immersion in trisbuffer solution. Table I Composition of samples (at \%.)

\section{EXPERIMENTAL PROCEDURE}

\section{A. Sample Preparation}

The powders of reagent grade were taken for the preparation of samples. Silicon dioxide $(\mathrm{Si})$, borate $\left(\mathrm{B}_{\mathrm{C}}\right)$, calcium carbonate $(\mathrm{C} \quad)$, sodium carbonate $\left(\mathrm{NaCO} \mathrm{CO}_{3}\right)$, and phosphorous pentoxide $(P \quad)$ were used to produce three different compositions of bioglass, which are described in Table I.

TABLE I THREE DIFFERENT COMPOSITIONS OF BIOGLASS

\begin{tabular}{|c|c|c|c|c|c|}
\hline Samples & & & CaO & & \\
\hline S1 & 40 & 10 & 20 & 25 & 5 \\
\hline S2 & 35 & 15 & 20 & 25 & 5 \\
\hline S3 & 30 & 20 & 20 & 25 & 5 \\
\hline
\end{tabular}

The total weight of each powder mixture was $25 \mathrm{gm}$. The powder mixtures were mixed and homogenized well with an agate mortar. Each powder was melted in an alumina crucible at $1350^{\circ} \mathrm{C}$. The borate and silica content were varied to check the effects of both on apatite generation. Each sample was initially placed inside the furnace at the temperature of $1000^{\circ} \mathrm{C}$ for half an hour to evaporate the moisture content from the melt. Then the temperature was increased to $1200^{\circ} \mathrm{C}$ and held for half an hour to escape all the gasses from it. Finally the temperature of melt was held at the temperature of $1350^{\circ} \mathrm{C}$ and kept for half an hour to make it more uniform and defect free. The melt of samples were poured in a graphite mold and then annealed at $500^{\circ} \mathrm{C}$ for 5 hours in another electric furnace to remove thermal stresses. The each sample was taken out from the furnace, when the furnace was off and having same temperature as 
atmosphere. The mold was pre heated at the annealing temperature, because it can cause thermal shock to samples when there is a huge temperature difference between melt and mold. Samples were taken out from the furnace when it has been cooled down to the atmospheric temperature, because slow cooling of glasses will allow it to settle well.

\section{B. In-Vitro Testing}

The in-vitro testing of bioglass samples was done with tris buffer solution for 21 days immersion. The temperature of the solution was kept at $37^{\circ} \mathrm{C}$. the $\mathrm{pH}$ of tris-buffer solution was 7.1 before immersion of samples.

\section{Sample Characterization}

The characterization of samples was done before and after immersion to check the behavior of samples in the solution.

\section{X-Ray Diffraction (XRD)}

XRD - (X'Pert Pro Panalytical PN - 3040/80 Almelo, Netherlands) was used for the XRD analysis of the samples. The $\mathrm{Cu} \mathrm{K} \alpha$ radiation was $(\lambda=1.540560)$ and the $2 \theta$ values were taken in the range of $20^{\circ}$ to $80^{\circ}$. The speed of scanning was $2^{\circ}$ per minute for each sample. The inter planner distances can be calculated by using the Bragg's formula.

\section{E. Scanning Electron Microscopy (SEM)/ Energy Dispersive Spectroscopy (EDS)}

In the proposed work testing was performed on SEM (JEOL $J S M-6610 L V$, A KISHIMA, JPN) machine. The samples were coated with conductive layer for this purpose.Both SEM and EDX were done before and after immersion in SBF at same magnification

\section{RESULTS AND DISCUSSION}

\section{A. pH Measurements}

The $\mathrm{pH}$ of samples was recorded at the interval of $72 \mathrm{hrs}$ repeadeatly. The total incubation time of imersion was 21 days (504 hrs). Initially the $\mathrm{pH}$ values were recorded decreased from 7.1 to 6.3 upto 220 hrs of immesion. After that the values incresed gradually between 6.8 to 7.2 upto $432 \mathrm{hrs}$ of immersion and then decreased as shown in figure 1 .

Initially the attack of $\mathrm{H}_{3}^{-} \mathrm{O}^{-}$and $\mathrm{OH}^{-}$ions on the bioglass takes place and then bioglass releases $\mathrm{Ca}^{2+}$ and $\mathrm{Na}^{2+}$ ions to the solution. The alkali ion addition to the SBF solution will cause increase in $\mathrm{pH}$ values. The release of sodium ions to the SBF exhibits in initially stages, that's why the $\mathrm{pH}$ of the solution decreased rapidly in initial stages.

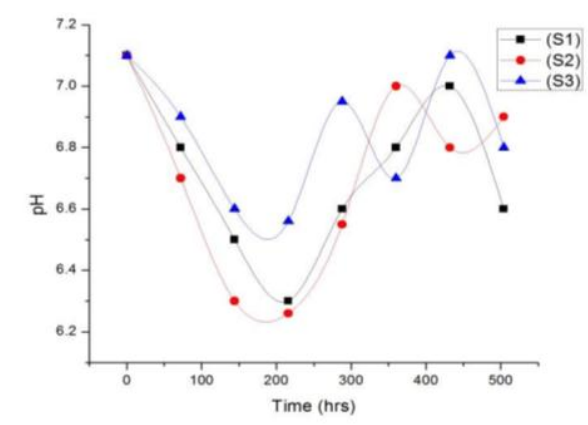

Fig. $1 \mathrm{pH}$ values of SBF at different intervals

After that the solution $\mathrm{pH}$ values increases and it also increases the kinetics of formation of $\mathrm{Ca}$ layer and apatite formation on the surface of the bioglass [12].

\section{B. XRD Analysis}

1. Before Immerson: The XRD data patterns shown that the all samples have clear and amorphous structure when melted at lower temperature. XRD data of all samples before and after immersion are showen in figures 2, 3 and 4. The sharp peaks were absent in the diffraction data patterns in all three samples before immersion. The amorphous hump was recorded in all samples before immersion. The amorphous hump of S1, S2 and S3 samples were recorded between $23^{\circ}$ to $35^{\circ}$.

2. After Immersion: The sharp peaks were appeared after immersion in SBF at $23.7^{\circ}, 31.9^{\circ}, 34^{\circ}$ and $72^{\circ}$ in S1, S2 and S3 XRD diffractin data patterns as shown in figures 3, 4 and 5. The peaks in $\mathrm{S} 1, \mathrm{~S} 2$ and $\mathrm{S} 3 \mathrm{XRD}$ diffractin data confirmed the apatite generation on the surfaces of the samples because these are caused by reactions in SBF [13].
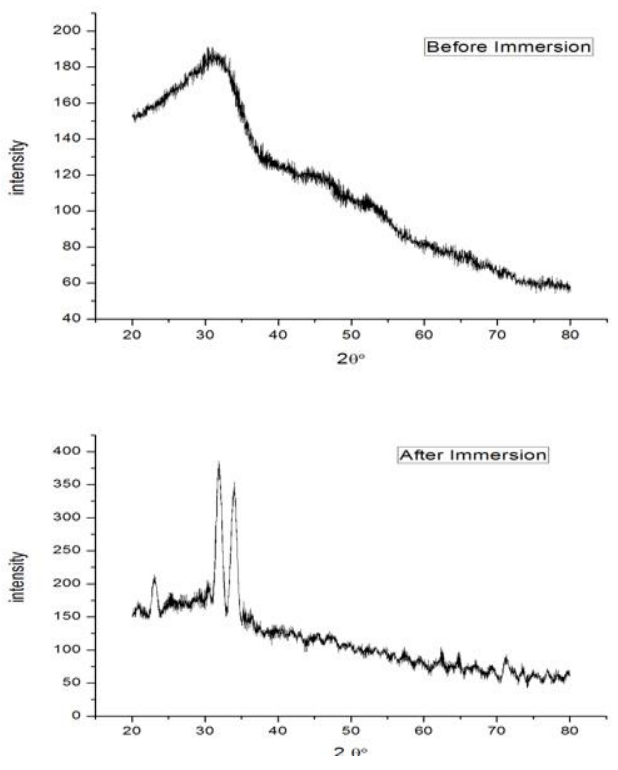

Fig. 2 XRD patterns of S1 before and after immersion 

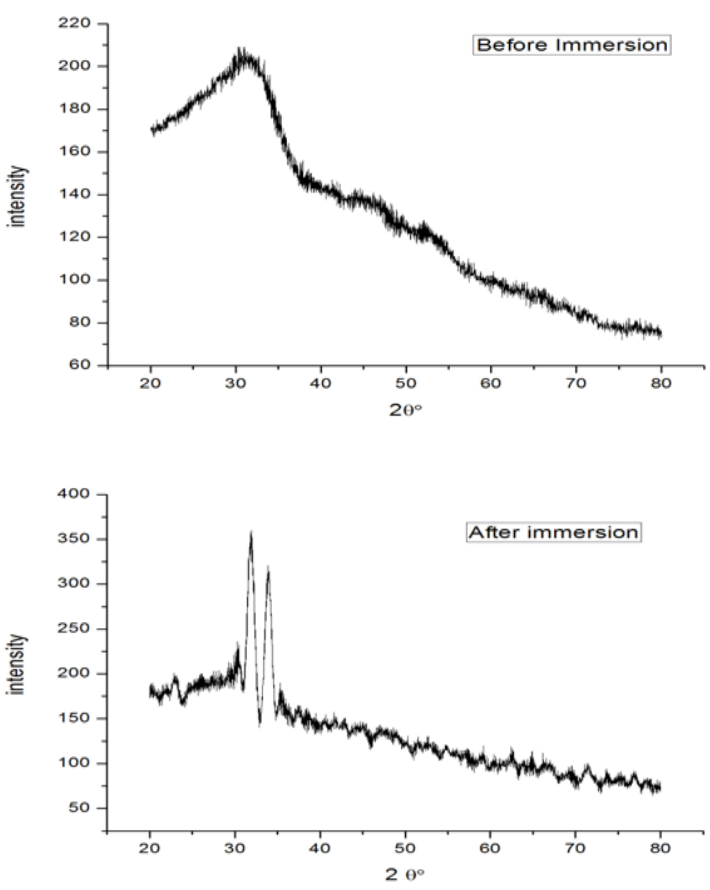

Fig. 3XRD patterns of S2 before and after immersion
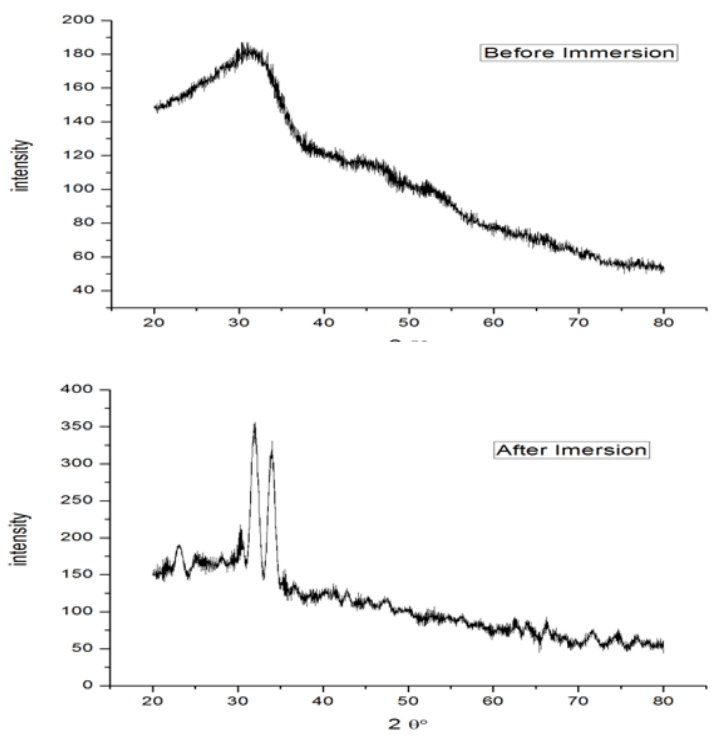

Fig. 4 XRD patterns of $\mathrm{S} 3$ before and after immersion

\section{SEM Analysis}

The changes were noticed by both SEM and EDX surface identification techniques. The results of samples S1, S2, S3 were recorded as positive index of apatite generation.

1. Before Immersion: The surfaces of the samples were clearly amorphous before immersion as shown in the figures 5, 6 and 7. All glass samples have clean surface and there is no aptite layer present on the surfaces of the samples. The samples are amorphous and the EDX data shown that the $\mathrm{Ca} / \mathrm{P}$ ratio of $\mathrm{S} 1, \mathrm{~S} 2$ and $\mathrm{S} 3$ samples is $2.37,2.32,2.41$ and respectively.

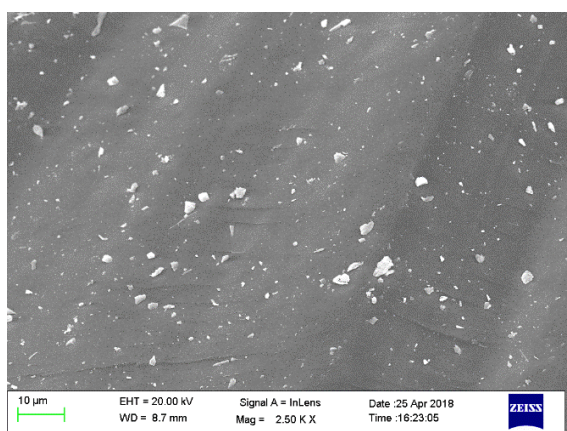

Fig. 5 SEM image of sample S1 before immersion

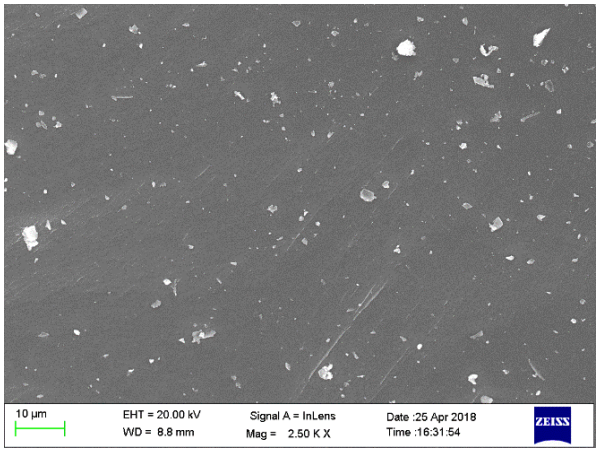

Fig. 6 SEM image of sample S1 before immersion

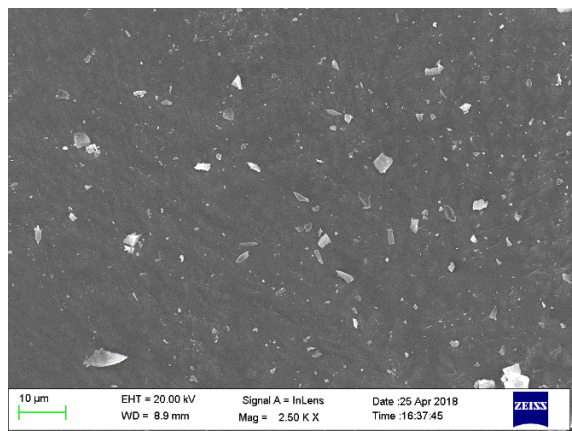

Fig. 7 SEM image of sample S1 before immersion

2. After Immersion : The apatite generation after immersion is appeared on the surfaces of S1, S2 and S3 after 21 days of immersion. The EDX reports also stated the change in $\mathrm{Ca} / \mathrm{P}$ ratio after immersion. The $\mathrm{Ca} / \mathrm{P}$ ratio of the bioglass should be higher than 1 to use in biomedical applications [13]. All the samples has $\mathrm{Ca} / \mathrm{P}$ ratio more than 1 before immersion. All the samples shown that the apatite layer begins to be appeared after immersion but did not covered the entire surface as shown in figures 8,9 and 10 .

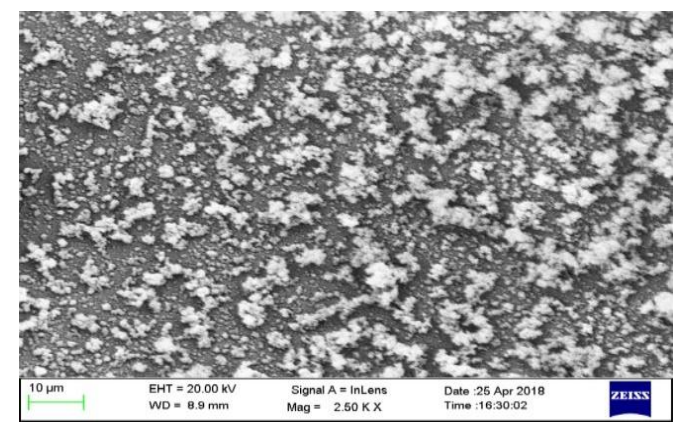

Fig. 8 SEM image of sample S1 after immersion 


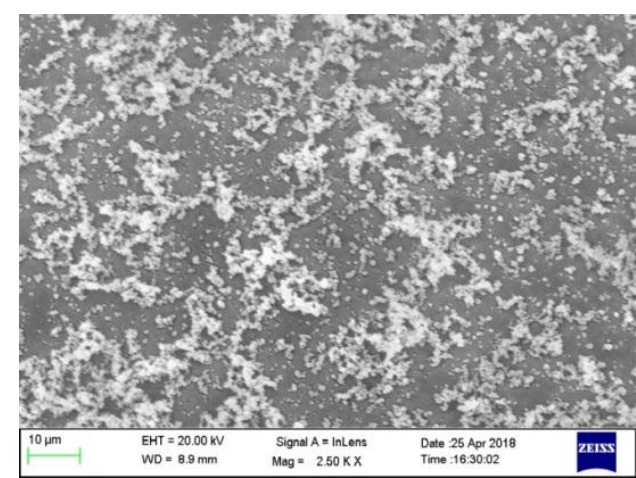

Fig. 9 SEM image of sample S2 after immersion

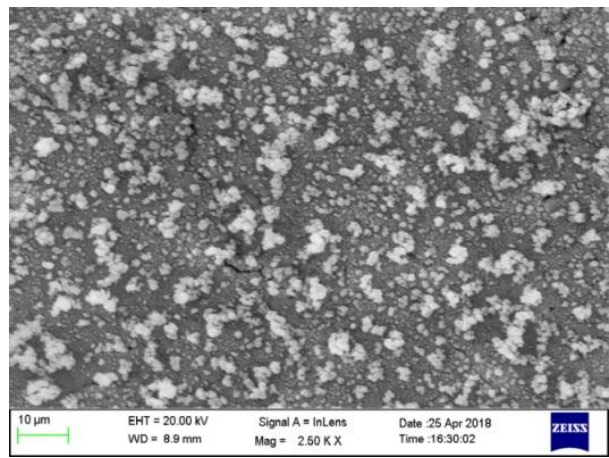

Fig. 10 SEM image of sample S1 after immersion

The $\mathrm{Ca} / \mathrm{P}$ ratio values of All samples before and after immersion were also different as shown below in the table 2 below;

TABLE II CA/P RATIO BEFORE AND AFTER IMMERSION

\begin{tabular}{|c|c|c|}
\hline Sample & $\begin{array}{c}\text { Ca/P Ratio before } \\
\text { immersion }\end{array}$ & $\begin{array}{c}\mathbf{C a} / \mathbf{P} \text { Ratio } \\
\text { after immersion }\end{array}$ \\
\hline $\mathrm{S} 1$ & 2.37 & 2.82 \\
\hline $\mathrm{S} 2$ & 2.32 & 2.59 \\
\hline $\mathrm{S} 3$ & 2.41 & 2.67 \\
\hline
\end{tabular}

The glass has higher $\mathrm{Ca} / \mathrm{P}$ ratio has higher tendancy to form $\mathrm{Ca}$ layer which is useful in biomedical applications than lower $\mathrm{Ca} / \mathrm{P}$ ratio after immersion [14].

\section{CONCLUSION}

In this present work three bioglass samples were prepared with mol\% variability of $\mathrm{SiO}_{2}$ and $\mathrm{B}_{2} \mathrm{O}_{3}$ to test their activeness in SBF. The different testing techniques $\mathrm{SEM} / \mathrm{EDX}, \mathrm{XRD}, \mathrm{pH}$ measurements, were performed for characterization. The samples were prepared using melt quench route. The samples were soaked in tris buffer solution for 21 days to check $\mathrm{pH}$ measurements due to reactions between samples and SBF. The SEM, XRD and EDX were reported before and after immersion of samples.
The apatite generation was founded on the surfaces of S1, S2 and S3 samples after 21 days of immersion. The changes on XRD data patteren clued the change of amorphous to crystalinity of samples. The SEM and EDX reports further confirmed the apatite generation on surfaces. The bioglass having $10 \%$ silica and $40 \%$ in mol\% (S1) borate content has more ability to form apatite layer on surface than S1 and S2.

\section{REFERENCES}

[1] J.R. Jones, and L.L. Hench, "Biomedical materials for new millennium: perspective on the future", Materials Science and technology, Vol. 17, No. 8, pp. 891-900, 2001

[2] Hench, L.L. Splinter, R.J. Allen, W.C. and T.K. Greenlee, "Bonding mechanisms at the interface of ceramic prosthetic materials", Journal of biomedical materials research, Vol. 5, No. 6, pp. 117-141, 1971.

[3] K. Sharma, S. Kedia, A.K. Singh C.B. A.K. Basak, Chauhan, S Basu, and S. Sinha, "Morphology and structural studies of laser treated 45S5 bioactive glass", Journal of Non-Crystalline Solids, Vol. 440, pp. 43-48, 2016.

[4] I. Rehman, L.L. Hench, W. Bonfield, and R. Smith, Analysis of surface layers on bioactive glasses. Biomaterials, Vol. 15, No. 10, pp. 865-870, 1994.

[5] S. Eqtesadi, A. Motealleh, P. Miranda, A. Pajares, Lemos, A. and Ferreira, J.M. 2014. Robocasting of 45S5 bioactive glass scaffolds for bone tissue engineering. Journal of the European Ceramic Society, Vol. 34, No. 1, pp. 107-118.

[6] I. Notingher, A.R. Boccaccini, J. Jones, V. Maquet, and L.L. Hench, "Application of Raman microspectroscopy to the characterisation of bioactive materials", Materials Characterization, Vol. 49, No. 3, pp. 255-260, 2002.

[7] A. Lucas-Girot, F.Z. Mezahi, M. Mami, H. Oudadesse, A. Harabi, and M. Le Floch, "Sol-gel synthesis of a new composition of bioactive glass in the quaternary system SiO2-CaO-Na2O-P2O5: comparison with melting method", Journal of Non-Crystalline Solids, Vol. 357, No. 18, pp. 3322-3327, 2011.

[8] P. Sepulveda, J.R. Jones, and L.L. Hench, "In vitro dissolution of melt-derived $45 \mathrm{~S} 5$ and sol-gel derived 58S bioactive glasses", Journal of Biomedical Materials Research: An Official Journal of The Society for Biomaterials, The Japanese Society for Biomaterials, and The Australian Society for Biomaterials and the Korean Society for Biomaterials, Vol. 61, No. 2, pp. 301-311, 2002.

[9] J.R. Jones, P. Sepulveda, and L.L. Hench, "Dose-dependent behavior of bioactive glass dissolution", Journal of Biomedical Materials Research: An Official Journal of The Society for Biomaterials, The Japanese Society for Biomaterials, and The Australian Society for Biomaterials and the Korean Society for Biomaterials, Vol. 58, No. 6, pp. 720-726, 2001.

[10] R. Hill, "An alternative view of the degradation of bioglass", Journal of Materials Science Letters, Vol. 15, No. 13, pp. 1122-1125, 1996.

[11] W. Leenakul, T. Tunkasiri, N. Tongsiri, K. Pengpat, and J. Ruangsuriya, "Effect of sintering temperature variations on fabrication of $45 \mathrm{~S} 5$ bioactive glass-ceramics using rice husk as a source for silica", Materials Science and Engineering: C, Vol. 61, pp. 695-704, 2016

[12] S.K. Yadav, S. Ray, M. Ershad, V.K. Vyas, S. Prasad, and A. Ali, "Development of Zirconia Substituted 1393 Bioactive Glass for Orthopaedic Application", Oriental Journal of Chemistry, Vol. 33, No. 6, pp. 2720-2730, 2017.

[13] N.F. Ibrahim, H. Mohamad, S.N.F.M. Noor, and N. Ahmad, "Meltderived bioactive glass based on $\mathrm{SiO} 2-\mathrm{CaO}-\mathrm{Na} 2 \mathrm{O}-\mathrm{P} 2 \mathrm{O} 5$ system fabricated at lower melting temperature", Journal of Alloys and Compounds, Vol. 732, pp. 603-612, 2018.

[14] D. Cheng, D. Liu, T. Tang, X. Zhang, X. Jia, Q. Cai, and X. Yang, "Effects of $\mathrm{Ca} / \mathrm{P}$ molar ratios on regulating biological functions of hybridized carbon nanofibers containing bioactive glass nanoparticles", Biomedical Materials, Vol. 12, No. 2, pp. 19, 2017. 